\title{
Complimentary Feeding Practices in Under-2 Children
}

\author{
Shanjoy Kumar Paul ${ }^{*}$ \\ Quazi Rakibul Islam² \\ Sunirmal Roy ${ }^{3}$ \\ Pranab Kumar Rudra ${ }^{4}$
}

'Department of Pediatric Nephrology

Sir Salimullah Medical College

Dhaka, Bangladesh.

${ }^{2}$ Department of Pediatrics

Green Life Medical College

Dhaka, Bangladesh.

${ }^{3}$ Department of Neonatology

Sir Salimullah Medical College

Dhaka, Bangladesh.

${ }^{4}$ Department of Pediatrics (Ex)

Feni Medical College

Feni, Bangladesh.

\section{*Correspondence to:}

\section{Dr. Shanjoy Kumar Paul}

Associate Professor of Pediatric Nephrology

Sir Salimullah Medical College

Dhaka, Bangladesh.

Mobile: +8801716330978

E-mail: drshanjoy@gmail.com shanjoykumarpaul@yahoo.com.au

\begin{abstract}
Background: Complimentary feeding (CF) practices are quiet frustating in our country. Innaproprite foods in first two years of life have detrimental impact on health and growth of children. The aim of the study was to see the present pattern of CF practices, to identify wrong practices and to develop awareness among medical professionals so that they may encourage appropriate practices more vigorously for reducing child mortality and morbidity. Methods: A cross-sectional study was conducted from October, 2011 to December, 2011 in the Pediatric department (indoor and outdoor) of Sir Salimullah Medical College Mitford Hospital, Dhaka and in a private chamber of a district town of Bangladesh. Four hundred motherchild pairs were selected by non-random convenience sampling method. 6-24 months old children and children under six months (if was on complimentary feeding) were included. Data was collected from the mothers/caregivers of the children in a pretested semi-structured data collection sheet and analyzed by SPSS version 12. Appropriate statistical tests were done. Statistical significance was considered if p value was $<0.05$. Results: Early initiation was very high $(49.25 \%)$. Most common first complimentary food was rice gruel with milk (26.56\%). Most common current main complimentary food $(25.52 \%)$ and most common main complimentary food fed in last 24 hours $(26.82 \%)$ was also rice gruel with milk. Amount of complimentary food per feed was inappropriate in most cases. Frequency of CF was not appropriate in many cases. Fast foods and commercial cereal were given to $54.8 \%$ \& $33.33 \%$ children respectively. Only $1 \%$ mothers/caregivers had sound knowledge about CF. Positive support from family regarding practicing appropriate CF was found in $24.75 \%$ cases. Feeding practices were mostly influenced by relatives (25\%). Conclusion: CF practices are still not ideal in our country. So, all possible interventions should be applied to improve it and thus to improve child survival.
\end{abstract}

Key words: Complimentary feeding; Practices; Mortality \& Morbidity.

\section{INTRODUCTION}

The nutritional needs of an infant from age six months onward can no longer be met with breast milk alone. To ensure adequate energy and nutrients, an infant's diet must be gradually expanded to include complimentary 'family foods'. The term 'complimentary' is important - these first foods compliment breast milk, not replace it. Continued breastfeeding for up to two years or beyond provides an essential source of energy and nutrients in the child's diet ${ }^{1}$.

Complimentary feeding (CF) should be timely, meaning that all infants should start receiving foods in addition to breast milk from 6 months onwards. It should be adequate, meaning that the complimentary foods should be given in amounts, frequency and consistency and using a variety of foods to cover the nutritional needs of the growing child while maintaining breastfeeding. WHO recommends that infants start receiving complimentary foods at 6 months of age in addition to breast milk, initially 2-3 times a day between 6-8 months, increasing to 3-4 times daily between 9-11 months and 12-24 months with additional nutritious snacks offered 1-2 times per day, as desired ${ }^{2}$. 
Appropriate complimentary foods can be readily consumed and digested by the young child from six months onwards and provides nutrients - energy, protein, fat and vitamins and minerals - to help to meet the growing child's needs in addition to breast milk ${ }^{3}$.

Often, complimentary foods are introduced too soon or too late. The frequency and amounts of food that is offered may be less than required for normal child growth, or their consistency or energy density may by inappropriate in relation to the child's needs. Conversely, too much of a poor complimentary food could displace the more nutritive breast milk in the child's diet. Other factors, such as the pattern of feeding (e.g., whether to breastfeed and follow it with complimentary foods, or vice versa) may affect breast milk intake. In addition, the nutrient content of these foods may be inadequate or the absorption could be impaired by other components in these foods. Storage safety is important as well ${ }^{4}$.

It is well recognized that the period from birth to two years of age is the "critical window" for the promotion of optimal growth, health, and development. Insufficient quantities and inadequate quality of complementary foods, poor child-feeding practices and high rates of infections have a detrimental impact on health and growth in these important years. An estimated six per cent or six hundred thousand under-five deaths can be prevented by ensuring optimal CF. Improved feeding of children under two years of age is particularly important because they experience rapid growth and development, are vulnerable to illness and there is evidence that feeding practices are poor in most developing countries. Continued breastfeeding beyond six months should be accompanied by consumption of nutritionally adequate, safe and appropriate complementary foods that help to meet nutritional requirements when breast milk is no longer sufficient ${ }^{3}$.

In our country, CF practices are not ideal. Feeding according to Infant and Young Child Feeding (IYCF) recommendation is quiet low during ages 6-8 months (6\%), increasing to $31 \%$ among 18-23 months old children. There are no differences between boys and girls. IYCF practice is better in urban areas than in rural areas (28\% versus $19 \%)$. IYCF practices improve with increasing education levels and wealth score ${ }^{5}$. So, severe acute and chronic malnutrition is still alarming. Inappropriate CF practices lead to development of many cases of diarrhea, severe acute respiratory infections, septicemia, oral thrush, allergic disorders which ultimately lead the children to high risk of morbidity and mortality. Though there have been considerable developments in breastfeeding and complementary feeding practices in the country, yet the scope for further progress is substantial ${ }^{6}$.

The aim of the study was to see the present pattern of $\mathrm{CF}$ practices, to identify wrong practices and to develop awareness among medical professionals so that they may encourage appropriate practices more vigorously for reducing child mortality and morbidity.

\section{MATERIALS \& METHODS}

This was a cross-sectional study conducted in the department of Pediatrics (outdoor and indoor), Sir Salimullah Medical College Mitford Hospital (SSMCMH), Dhaka and from a private chamber in a district town (Gazipur) of Bangladesh from October, 2011 to December, 2011. Four hundred motherchild pairs were included by non- random convenience sampling who came to hospital and private chamber for treatment, vaccination and as attendants. Data was collected in a predefined semi-structured data collection sheet from the mothers/caregivers of the children who took about 20-30 minutes in each case. Children aged 6-24 months and children less than six months (if CF was started) were included. Children under six months (if on exclusive breast feeding) and children having major illness interfering with feeding (e.g. cerebral palsy, congenital heart disease and cleft palate) were excluded after taking history and physical examination.

\section{CASE DEFINITIONS}

Complimentary foods: Khichuri, Mixed family foods (Rice, pulses, vegetables, meat, egg, fish etc.), Bread, Pitha, Noodles, Fruits, Locally processed complementary foods, Rice gruel, Rice gruel with Sugar, Rice gruel with milk, Suji (Wheat), Suji with Milk, Suji with Sugar, Sugar water, Sago, Burly, Animal milk, Formula, Commercial cereal, Fast foods etc.

Appropriate complimentary foods: Khichuri, Mixed family foods (Rice, pulses, vegetables, meat, egg, fish etc.), Bread, Pitha, Fruits, Locally processed complimentary foods etc.

Inappropriate complimentary foods - Rice gruel, Rice gruel with Sugar, Rice gruel with Milk, suji (Wheat), Suji with Milk, Suji with Sugar, Sugar water, Sago, Burly, Animal milk, Formula, Commercial cereal, Fast foods etc.

Fast foods: Foods those are tasty, easily cooked, easily available and gladly accepted by children (e.g. Burger, Sandwich, French fries, Pizza, Hot dog, Noodles, Fried chicken, Chips, Biscuits, Soft drinks, Commercial juices etc.)

Frequency of complimentary feeding was defined according to recommendation of Integrated Management of Childhood Illness (IMCI) by WHO/UNICEF. Amount of complimentary food was defined according to IYCF recommendation.

Knowledge about CF was assessed by asking about optimum initiation time, type of recommended complimentary foods, frequency and amount.

Data analysis: Data were analyzed by SPSS version 12 . Bivariate tables were prepared. Chi square tests were done where applicable. Statistical significance was considered if $\mathrm{p}$ value $<0.05$.

Ethical consideration: Verbal consent was taken from the mothers/caregivers of the children after discussion about the study. Permission was taken from the ethical committee of SSMCMH, Dhaka, Bangladesh. 


\section{RESULTS}

Out of 400 mother-child pairs, 274 (68.7\%) were selected from out-patient department, 26 (6.3\%) from indoor and 100 (25\%) from a private chamber. Both father and mother were alive in all cases. 98.2\% $(n=393)$ mothers used to live with their husbands. Mothers were informant in 388 cases (97\%), father in one $(0.25 \%)$ and others in $11(2.75 \%)$.

Mother was housewife in 377 cases $(94.25 \%)$, followed by handicraft worker in eight $(2 \%)$, service holder in six $(1.5 \%)$, maid servant in four $(1 \%)$, garment worker in one $(0.25 \%)$, businessman in one $(0.25 \%)$ and others in three $(0.75 \%)$. Father was service holder in 176 cases $(44 \%)$, followed by businessman in $133(33.2 \%)$, day labor in $34(8.5 \%)$, driver in $25(6.2 \%)$, farmer in $12(3 \%)$, rickshaw puller in $11(2.8 \%)$, unemployed in seven (1.8\%) and others in two $(0.5 \%)$. Father's education had significant influence only on frequency of $\mathrm{CF}$ $(\mathrm{p}=0.007)$. Monthly income was $>15000$ taka in $35 \%(\mathrm{n}=140)$ families followed by 5001-10000 taka in 33\% ( $\mathrm{n}=132), 5000$ taka in $17.8 \%(\mathrm{n}=71)$ and $10001-15000$ taka in $14.2 \%(\mathrm{n}=57)$. Bigger family size (5-10 members) had significant influence on current main complimentary food only ( $\mathrm{p}=0.045)$.

Most $(59.2 \%, \mathrm{n}=237)$ of the children were delivered in hospital. Mode of delivery was vaginal in $60.8 \%$ and lower uterine caesarian section in $39.2 \%$ cases. Order of birth was first in $49.8 \%$ cases followed by second (32\%), third (14.2\%), fourth $(3.2 \%)$, fifth $(0.5 \%)$ and sixth $(0.2 \%)$. Pre-lacteal feeding was given to $38.8 \%$ cases $(n=155)$. Initiation of breastfeeding within one hour was in $29 \%$ cases $(n=108)$.

CF was initiated within four months of age in 60 children (15\%), between 5-6 months in 137 (34.25\%), at seventh month in 137 (34.25\%). Fifty children (12.5\%) were started CF after seven months and $16(4 \%)$ were not started at all at the time of interview.

Most mothers started CF early due to the perception that their babies were not getting enough breast milk ( $\mathrm{n}=99,24.75 \%)$, by advice of elderly members of the family $(n=10,2.5 \%)$ and due to lack of knowledge about time of initiation of $\mathrm{CF}(\mathrm{n}=5$, $1.25 \%$ ). Reasons for late initiation were baby's refusal of complimentary foods $(n=30,7.5 \%)$, lack of knowledge about initiation time of CF ( $n=11,2.75 \%)$, discouragement by elderly members of the family $(n=8,2 \%)$, mother's perception that their babies were getting enough breast milk $(n=8,2 \%)$ etc.

Religious barrier was found in 11 cases only $(2.86 \%)$. Cultural barrier was present in 91 cases $(23.70 \%)$ and statistically insignificant $(\mathrm{p}>0.05)$. Pressure of housework was present in $13.6 \%(\mathrm{n}=54)$ mothers/caregivers. Blender machine for preparing complementary foods was used by 29 (7.55\%). Family members knew well about CF in three cases $(0.75 \%)$, something in $379(94.75 \%)$ and nothing in 18 (4.50\%). Inappropriateness in the frequency of CF was observed more in first-born children ( $\mathrm{n}=90,46.6 \%)$ with declining to zero in lastborn.
Among 15 normal children who came to hospital as attendant and for vaccination, time of initiation of CF was appropriate in eight $(57.1 \%)$ and inappropriate in six (42.9\%); type of first complementary food was appropriate in seven $(46.7 \%)$ and inappropriate in eight (53.3\%); main complimentary food was appropriate in eight $(53.3 \%)$ and inappropriate in seven (46.7\%); frequency of CF was appropriate in seven (50\%) and inappropriate in seven (50\%).

Among 385 sick children, time of initiation of CF was appropriate in 179 (48.4\%) and inappropriate in 191 (51.6\%); type of first complimentary food was appropriate in 101 $(26.4 \%)$ and inappropriate in 282 (73.6\%); main complimentary food was appropriate in 148 (38.6\%) and inappropriate in 235 (61.4\%); frequency of CF was appropriate in $206(56.4 \%)$ and inappropriate in 159 (43.6\%).

Table 1: Socio-demographic profile $(n=400)$

\begin{tabular}{|c|c|c|}
\hline Status & Number & Percentage \\
\hline \multicolumn{3}{|l|}{ Age } \\
\hline$\leq 6$ months & 23 & 5.75 \\
\hline 7-24 months & 377 & 94.25 \\
\hline \multicolumn{3}{|l|}{ Sex } \\
\hline Male & 226 & 56.5 \\
\hline Female & 174 & 43.5 \\
\hline \multicolumn{3}{|l|}{ Residence } \\
\hline Rural & 113 & 28.25 \\
\hline Urban & 225 & 56.25 \\
\hline Semi-urban & 61 & 15.25 \\
\hline Urban slum & 1 & 0.25 \\
\hline \multicolumn{3}{|l|}{ Health status } \\
\hline Sick & 385 & 96.25 \\
\hline Healthy & 15 & 3.75 \\
\hline \multicolumn{3}{|l|}{ Religion } \\
\hline Islam & 363 & 90.8 \\
\hline Hinduism & 37 & 9.2 \\
\hline \multicolumn{3}{|l|}{ Caregiver } \\
\hline Mother & 385 & 96.2 \\
\hline Others & 15 & 3.8 \\
\hline \multicolumn{3}{|l|}{ Family status } \\
\hline Single & 272 & 68 \\
\hline Joint & 128 & 32 \\
\hline $\begin{array}{l}\text { Positive support } \\
\text { from family }\end{array}$ & 99 & 24.75 \\
\hline \multicolumn{3}{|c|}{$\begin{array}{l}\text { Received nutrition } \\
\text { education by health }\end{array}$} \\
\hline \multicolumn{3}{|c|}{$\begin{array}{l}\text { Mothers/caregivers } \\
\text { knowledge about } \mathrm{CF}\end{array}$} \\
\hline Knows well & 4 & 1 \\
\hline Knows something & 389 & 97.2 \\
\hline Knows nothing & 7 & 1.8 \\
\hline \multicolumn{3}{|c|}{$\begin{array}{l}\text { Mothers/caregivers } \\
\text { positive attitude }\end{array}$} \\
\hline towards $\mathrm{CF}$ & 334 & 83.5 \\
\hline
\end{tabular}


Table 2: Different types of feeding practices $(n=400)$

\begin{tabular}{lcr} 
Feeding practices & Number & Percentage \\
$\begin{array}{l}\text { Exclusive breast-feeding } \\
\text { For one month }\end{array}$ & 216 & 54 \\
For six months & 39 & 9.75 \\
$\begin{array}{l}\text { Current breast feeding status } \\
\text { Partial }\end{array}$ & 335 & 83.8 \\
$\begin{array}{l}\text { No breast feeding } \\
\text { Animal milk } \\
\text { (cow/goat) }\end{array}$ & 65 & 16.2 \\
Formula feeding & 228 & 57 \\
Bottle feeding & 283 & 70.8 \\
Complimentary & 297 & 74.2 \\
feeding & & 96 \\
Commercial cereal & 384 & 33.33 \\
Fast foods & 128 & 51.5 \\
\hline
\end{tabular}

Table 3 : Current feeding practices influenced by $(n=400)$

\begin{tabular}{lcr} 
Influenced by & Frequency & Percentage \\
Relatives & 100 & $25 \%$ \\
Qualified doctors & 61 & $15.3 \%$ \\
Neighbors & 58 & $14.5 \%$ \\
Mother-in-law & 54 & $13.5 \%$ \\
Husband & 25 & $6.3 \%$ \\
Television & 24 & $6 \%$ \\
Other family members & 20 & $5 \%$ \\
Other health workers & 9 & $2.3 \%$ \\
Friends & 1 & $0.3 \%$ \\
Newspapers & 1 & $0.3 \%$ \\
Others & 47 & $11.5 \%$ \\
\hline
\end{tabular}

Table 4 : Inappropriate amount of complimentary foods/feed

Amount Number Percentage Total

7 months: $<2-3$ tablespoonfuls $\quad 13 \quad 36 \quad 36$

8 months: $<2 / 3$ of a $250 \mathrm{ml}$ cup or

more than $3 / 4$ of a $200 \mathrm{ml}$ cup

$\begin{array}{llll}\text { at each meal } & 38 & 95 & 40\end{array}$

9-11 months: $<3 / 4$ of a $250 \mathrm{ml}$ cup or full $200 \mathrm{ml}$ cup at each meal

12-24 months: <a full $250 \mathrm{ml}$ cup/bowl or more than a full $200 \mathrm{ml}$ cup/bowl $\quad 186 \quad 97.4 \quad 191$
Table 5 : Effect of mother's education on complimentary feeding practices $(n=400)$

\begin{tabular}{|c|c|c|c|c|c|}
\hline Effect on & $\begin{array}{l}\text { No } \\
\text { education }\end{array}$ & $\begin{array}{l}\text { Primary } \\
\text { incomplete }\end{array}$ & $\begin{array}{l}\text { Primary } \\
\text { complete }\end{array}$ & $\begin{array}{l}\text { Secondary } \\
\text { incompleteq }\end{array}$ & $\begin{array}{l}\text { Secondary Total } \\
\text { complete or } \\
\text { higher }\end{array}$ \\
\hline
\end{tabular}

Initiation

0.275

$\begin{array}{lllllll}\text { Appropriate } & 17(35.4 \%) & 33(56.9 \%) & 11(52.4 \%) & 86(48.6 \%) & 40(50 \%) & 187(48.7 \%)\end{array}$

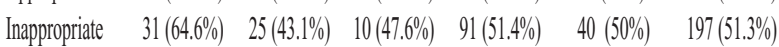

\section{Type of first}

complimentary food

$\begin{array}{lllllll}\text { Appropriate } & 12(25 \%) & 21(34.4 \%) & 5(21.7 \%) & 51(27.6 \%) & 19(23.5 \%) & 108(27.1 \%)\end{array}$ $\begin{array}{lllllll}\text { Inappropriate } & 36(75 \%) & 40(65.6 \%) & 18(78.3 \%) & 134(72.4 \%) & 62(76.5 \%) & 290(72.9 \%)\end{array}$

Main

complimentary food

$\begin{array}{lllllll}\text { Appropriate } & 23(46.9 \%) & 31(50 \%) & 8(36.4 \%) & 69(37.3 \%) & 25(31.2 \%) & 156(39.2 \%)\end{array}$

$\begin{array}{lllllll}\text { Inappropriate } & 26(53.1 \%) & 31(50 \%) & 14(63.6 \%) & 116(62.7 \%) & 55(68.8 \%) & 242(60.8 \%)\end{array}$

Frequency of CF 0.006

$\begin{array}{lllllll}\text { Appropriate } & 18(38.3 \%) & 28(49.1 \%) & 9(42.9 \%) & 104(59.4 \%) & 54(68.4 \%) & 213(56.2 \%)\end{array}$

$\begin{array}{lllllll}\text { Inappropriate } & 29(61.7 \%) & 29(50.9 \%) & 12(57.1 \%) & 71(40.6 \%) & 25(31.6 \%) & 166(43.8 \%)\end{array}$

Significant influence only on frequency of CF

Table 6 : Frequency of complimentary feeding - appropriate or not $(n=379)$

Frequency Appropriate Inappropriate Total

Age $\leq 12$ months

$\geq 3$ times / day if breast-fed $\quad 77.9 \% \quad 22.1 \% \quad 181$

$\geq 5$ times / day if not breast-fed $\quad 51.3 \% \quad 48.7 \% \quad 39$

Age 13-24 months

$\begin{array}{llll}\geq 5 \text { times / day } & 23.9 \% & 76.1 \% & 159\end{array}$

Table 7 : Type of first complimentary foods $(n=384)$

\begin{tabular}{lcc}
$\begin{array}{l}\text { First complimentary } \\
\text { foods }\end{array}$ & Number & Percentage \\
Rice gruel with milk & 102 & 26.56 \\
Khichuri & 71 & 18.49 \\
Suji with milk & 63 & 16.41 \\
Commercial cereal & 58 & 15.10 \\
Rice gruel alone & 37 & 9.64 \\
Mixed family foods & 26 & 6.77 \\
Suji & 10 & 2.60 \\
Fruits & 9 & 2.34 \\
Sago & 3 & 0.78 \\
Burly & 2 & 0.52 \\
Others & 3 & 0.78 \\
\hline
\end{tabular}


Table 8 : Current main complimentary foods $(n=384)$

\begin{tabular}{lcr} 
Current main & Number & Percentage \\
complimentary foods & & \\
Rice gruel with milk & 98 & 25.52 \\
Mixed family foods & 83 & 21.61 \\
Khichuri & 62 & 16.15 \\
Suji with milk & 54 & 14.06 \\
Commercial cereal & 24 & 6.25 \\
Suji & 8 & 2.08 \\
Rice gruel alone & 8 & 2.08 \\
Rice with lentils & 7 & 1.82 \\
Rice gruel with sugar & 6 & 1.56 \\
Sago & 5 & 1.30 \\
Locally processed & & \\
complimentary foods & 2 & 0.52 \\
Burly & 1 & 0.26 \\
Noodles & 1 & 0.26 \\
Egg & 1 & 0.26 \\
Pitha & 1 & 0.26 \\
Others & 23 & 5.99 \\
\hline
\end{tabular}

Table 9 : Main complimentary foods fed in last 24 hours $(n=384)$

\begin{tabular}{lcr} 
Main complimentary foods & Number & Percentage \\
Rice gruel + Milk & 103 & 26.82 \\
Mixed family food & 79 & 20.57 \\
Khichuri & 59 & 15.36 \\
Suji + Milk & 52 & 13.54 \\
Commercial Cereal & 24 & 6.25 \\
Animal Milk & 19 & 4.95 \\
Rice gruel & 10 & 2.60 \\
Suji & 8 & 2.08 \\
Rice + Lentils & 7 & 1.82 \\
Rice gruel + Sugar & 6 & 1.56 \\
Fruits & 5 & 1.30 \\
Sago & 4 & 1.04 \\
Bread & 2 & 0.52 \\
Locally processed & & \\
complimentary foods & 2 & 0.52 \\
Burly & 1 & 0.26 \\
Noodles & 1 & 0.26 \\
Egg & 1 & 0.26 \\
Pitha & 1 & 0.26 \\
\hline
\end{tabular}

\section{DISCUSSION}

CF practices were found to be unsatisfactory in this study. There was a large gap between actual current CF practices and that recommended in our country. Early initiation was still high. Rice gruel with milk was the first choice as first complimentary food and current main complimentary food which is not recommended. Frequency and amount of complimentary foods were not ideal. Fast foods \& commercial cereal feeding were alarming.
Early initiation of $\mathrm{CF}$ is a great problem in Bangladesh like many other countries. $30 \%, 28 \%$ and $22 \%$ mothers started $\mathrm{CF}$ before five months in two rural areas and in an urban slum (Dhaka city) of Bangladesh respectively ${ }^{7-9}$. Two studies from Malaysia and Brazil had shown similar picture ${ }^{10-11}$. In USA, two studies showed that $21 \%$ of the mothers introduced solid foods before four months and early introduction of solid foods was common among low-income women ${ }^{12-13} .34 \%$ mothers started complimentary foods before four months of age in Italy, 16\% before three months in Germany and $51 \%$ before four months in $\mathrm{UK}^{14-16}$. In Pokhara municipal area (Nepal), nearly $40 \%$ mothers initiated CF before recommended six months ${ }^{17}$. In rural China, approximately one third of children started $\mathrm{CF}$ at 4-6 months and $16.4 \%$ children were fed cereal foods before four months of age ${ }^{18}$. Zanban and porridge were offered at about one month after birth in Tibet ${ }^{19}$. In United Arab Emirates, $83.5 \%$ infants received solid foods before the age of six months and even since birth in $24.1 \%$ cases $^{20}$. Over $40 \%$ of Malawian infants received complimentary foods by two months and $65 \%$ by three months ${ }^{21}$. So, the picture is similar in both rich and poor countries indicating inappropriate $\mathrm{CF}$ practices everywhere. Early CF was significantly associated with increased risk for respiratory infection $(\mathrm{p}<0.05)$, and marginally increased risk for eye infection and episodes of malaria. Maternal illiteracy was associated with early $\mathrm{CF}$ $(\mathrm{OR}=2.1,95 \% \mathrm{CI} 1.3,3.2)$, while later $\mathrm{CF}$ was associated with reduced infant morbidity and improved growth ${ }^{21}$.

Rice gruel with milk as first complimentary food is not an appropriate choice though majority of mothers/caregivers practiced it in this study. Rice is the main staple food in our country. Animal milk is considered as highly nutritious food for children in our society. So, they practice milk alone or with rice gruel, suji, sago, burly etc. In a rural community of Malaysia, commercial cereal (Nestum) was most commonly used as the first weaning food ${ }^{10}$.

Current main complimentary food was also rice gruel with milk which is obviously inappropriate. $64 \%$ of mothers were using dal water as main weaning food in a locality of India ${ }^{22}$. Two studies done in a rural community and in a slum of Dhaka city of Bangladesh had shown family foods as major complementary food $(47.1 \% \text { \& } 36.8 \% \text { respectively })^{8-9}$. Khichuri was the main complimentary food $(49.7 \%)$ in another study in a rural area of Dhaka ${ }^{23}$. Our samples were representatives of different parts of the country including towns, villages and urban slums.

Feeding of commercial cereal is a panic now-a- days. Mothers are easily convinced by its attractive packaging, easy availability, easy preparation, more accepted by baby once introduced, aggressive marketing policy of the companies etc. It is a status-symbol to many mothers/caregivers too. It is an

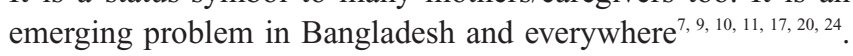
Once a baby tastes it, he/she does not like natural family foods in most cases, which causes extra economic burden to the family and increased risk of health hazards to the child.

Though fast food culture is criticized everywhere, it has been spreading rapidly in our country. 
In USA, many mothers fed commercial baby juice to their babies even before 6 months of age, which was peak at nine months ${ }^{12}$. Another study from USA also showed that lowincome mothers fed excessive juices and sugary drinks to their children $^{13}$. A lot of convenience foods were being used these days by mothers of India like biscuits, marketed weaning foods and fast foods like noodles, fried savory items etc ${ }^{25}$. These are non-nutritious foods. They lack in many vitamins, minerals and contain hydrogenated fats, preservatives which may harm their health. Besides these, fast foods interfere with intake of normal family foods. Many guardians know it, but they are reluctant to avoid it.

Fruit juices, soup, tea etc. are less practiced in our country. In Brazil, these foods are widely used ${ }^{26}$. These are practiced in India too ${ }^{25}$. About 30\% infants in United Arab Emirates were given non-milk fluids such as Anis seed drink (Yansun), grippe water and tea before three months of age ${ }^{20}$.

When joint family culture was more in our society, elderly persons of the family, especially mother-in-laws used to guide and influence the mothers about CF. In the present study, most families were single. So, majority of mothers were influenced by relatives other than family members. But due to similar wrong conception within most of the peoples, feeding practices are not improving to an acceptable level. In India, elderly women like mothers-in law generally influence and guide child feeding practices in the family who has incorrect knowledge about $\mathrm{CF}^{27}$. Another study in 100 infants from same country shows that feeding practices were influenced by multiple persons/factors, mostly by elders in the family - mother-in-law and grandmother $(n=37)$ followed by self $(n=33)$, friends $(n=27)$, medical peoples $(n=21)$, neighbors $(n=16)$, books/media/internet $(n=16)$, husbands $(n=13)^{25}$.

Knowledge of mothers/caregivers and family members about $\mathrm{CF}$, positive family support for $\mathrm{CF}$, nutrition education etc. were not satisfactory in this study. In China, it was seen that an educational intervention (through group trainings and home visits) delivered through local health-care providers could lead to substantial behavioral changes of caregivers and improve infant growth ${ }^{28}$.
There were some limitations in the study e.g. non- random convenience sampling design, recall biasness, relatively small number of rural samples etc.

\section{RECOMMENDATION}

Nutrition education to the mothers/caregivers, family members and general peoples should be emphasized through local health care providers and all other possible opportunities should be utilized more effectively to increase awareness so that their attitude and practice are changed a lot to improve child survival.

\section{ACKNOWLEDGEMENTS}

We are grateful to Swedish International Development Agency (Sida), Sweden for support to conduct the study as a part of the training program on 'Child Survival - Reaching the Target' and Prof. Lars-Ake Persson, Department of Women's and Children's Health, Uppsala University, Sweden for his continuous supervision \& guidance during the study.

\section{CONCLUSION}

CF practice is a dark zone in our health care delivery system. Time of initiation is ideal in only one third children. Rice gruel with milk is still practiced widely. Mothers/caregivers have inadequate knowledge about type \& amount of complimentary food and its frequency. Many dangerous wrong practices are going on e.g. bottle feeding, feeding during sleep, feeding of commercial foods etc. Positive support from family is insignificant. Impact of academic and nutrition education is unsatisfactory. Relatives, family members and neighbors are playing main role in $\mathrm{CF}$ practices.

\section{DISCLOSURE}

All the authors declared no competing interest. 


\section{REFERENCES}

1. World vision international. Complimentary feeding file://G:ICF-All articles-CF\Articles on CF \Complimentary Feeding_World Vision I. 12/15/2013.

2. World Health Organization. Nutrition. Complementary feeding file://G:ICF-All articles-CF\Articles on CF\WHO_Complimentary feeding.htm 12/15/2013.

3. UNICEF. Nutrition. Complimentary Feeding. Updated: 13 January 2005 file://G:ICF-All articles-CF\Articles on CF\UNICEFNutrition - Complimentary Fee. 12/15/2013.

4. UNICEF Home. Complimentary Foods and Feeding: Nutritional companion to breastfeeding after 6 months. 18 December 2013.

5. National Institute of Population Research and Training, Mitra and Associates, Dhaka, Bangladesh and MEASURE DHS, ICF International, Calverton, Maryland, U.S.A. Bangladesh demographic and health survey 2011: Preliminary report. April 2012.

6. Hanif HM. Trends in infant and young child feeding practices in Bangladesh, 1993-2011. International breastfeeding Journal. $2013 ; 8$ : 10.

7. Haque MJ, Rahman MM, Sarker SK, Ali MA, Fakir M, Rahman MM, Islam MM. Infant Feeding Practice by the Rural Mothers of Dinajpur District. Dinajpur Med Col. J 2010; 3(1): 35-38.

8. Islam MZ, Farjana S, Masud JHB. Complimentary feeding practices among the mothers of a rural community. Northern International Medical College Journal. 2012; 3(2): 204-207.

9. Akhtar K, Hoque ME, Islam MZ, Yusuf MA, Sharif AR, Ahsan AI. Feeding Pattern and Nutritional Status of Under Two Years Slum Children. J Shaheed Suhrawardy Med Coll. 2012; 4(1): 3-6.

10. Zulkifli A, Kyi DW, Rahman AI. Breast feeding and weaning practices in rural communities of Kelantan, Malaysia. Mal J Nutr. 1996; 2: 148-154.

11. Lindsay AC, Machado MT, Sussner KM, Hardwick CK, Peterson KE. Infant-feeding practices and beliefs about complimentary feeding among low-income Brazilian mothers: a qualitative study. Food Nutr Bull. 2008; 29 (1): 15-24.

12. Fein SB, Labiner-Wolfe J, Scanlon KS, Grummer-Strawn LM. Selected Complimentary Feeding Practices and Their Association With Maternal Education. Pediatrics. 2008; 122 (Supplement 2): S91 -S97.

13. Jane H, Jennifer F, Kara I, Katherine KP, Roberta C, Jeanette P. Barriers to compliance with infant-feeding recommendations among low-income women. Journal of Human Lactation. 2006; 22(1). http://www.ars.usda.gov/research/publications.htm?seq_no_115=196541 (accessed on 2011-04-05).

14. Giovannini M, Riva E, Banderali G, et al. Feeding practices of infants through the first year of life in Italy. Acta Paediatr. 2004; 93: 492-497.

15. Koletzko B, Dokoupil K, Reitmayr S, et al. Dietary fat intake in infants and primary school children in Germany. Am J Clin Nutr. 2000; 72: 1392-1398

16. Bolling K, Grant C, Hamlyn B, et al. Infant Feeding Survey 2005. PL London:PN The Information Centre, National Health Service. 2007.

17. Subba SH, Chandrashekhar TS, Binu VS, Joshi HS, Rana MS, Dixit SB. Infant Feeding Practices of mothers in an urban area in Nepal. Kathmandu University Medical Journal. 2007; 5 (1): 42-47.

18. He YN, Zhai F. Complimentary feeding practice in Chinese rural children. Wei Sheng Yan Jiu. 2001; 30(5): 305-7.

19. Dang S, Yan H, Yamamoto S, Wang X, Zeng L. Feeding practice among younger Tibetan children living at high altitudes. Eur J Clin Nutr. 2005; 59(9): 1022-1029.

20. Radwan H. Patterns and determinants of breastfeeding and complimentary feeding practices of Emirati mothers in the United Arab Emirates. BMC Public Health. 2013; 13: 171

21. Kalanda BF, Verhoeff FH, Brabin BJ. Breast and complimentary feeding practices in relation to morbidity and growth in Malawian infants. Eur J Clin Nutr. 2006; 60(3): 401-407.

22. Dhingra Bhavan, Mishra Devendra, Arora Prem. Dal water as a weaning food: a common but inappropriate practice. Indian J Pediatr. 2007; 74: 962-963.

23. Dr. Mohoshina Karim, Dr. Shayela Farah, Dr. Jannatul Ferdousi. Study on feeding practices of infants among the mothers in selected villages, at Dhamrai. J. Dhaka National Med. Coll. Hos. 2012; 18(02): 30-36.

24. Sima roy, Aparajita Dasgupta, Bobby Pal. Feeding Practices of Children in an Urban Slum of Kolkata. Indian J Community Med. 2009; 34(4): 362-363.

25. Shivani Lodha, Vandana Bharti. Assessment of complimentary feeding practices and misconceptions regarding foods in young mothers. International Journal of Food and Nutritional Sciences. 2013; 2(3): 85-90.

26. Cristina Maria Garcia de Lima Parada, Maria Antonieta de Barros Leite Carvalhaes, Milena Temer Jamas. Complimentary feeding practices to children during their first year of life. Rev. Latino-Am. Enfermagem 2007 March/April ; 15 (2), http://dx.doi.org/10.1590/S0104-11692007000200014

27. Kumudha A, Khan ME, Hazra A. Increasing appropriate complimentary feeding in rural Uttar Pradesh. The Journal of Family Welfare. 2010; 56: 51-56.

28. Shi L, Zhang J, Wang Y, Caulfield LE, Guyer B. Effectiveness of an educational intervention on complimentary feeding practices and growth in rural china: a cluster randomized controlled trial. Public Health Nutr. 2010; 13(4): 556-65. Epub 2009 Aug 26. 